\title{
Identification of the NF- $\kappa$ B inhibitor A20 as a key regulator for human adipogenesis
}

\author{
A Dorronsoro ${ }^{1,3}$, V Lang ${ }^{2,3}$, E Jakobsson ${ }^{1}$, I Ferrin ${ }^{1}$, JM Salcedo ${ }^{1}$, J Fernández-Rueda ${ }^{1}$, K Fechter ${ }^{1}$, MS Rodriguez ${ }^{2}$ and C Trigueros ${ }^{\star, 1}$
}

The zinc-finger protein A20 is a key player in the negative feedback regulation of the nuclear factor kappa-light-chain-enhancer of activated B-cell (NF- $\kappa$ B) pathway in response to multiple stimuli. Tumor necrosis factor alpha (TNF $\alpha$ ), a cytokine with pleiotropic effects on cellular proliferation and differentiation, dramatically increases A20 expression in all tissues. As TNF $\alpha$ inhibits adipocyte differentiation, we have determined the contribution of A20 to the adipogenic capacity of human mesenchymal stromal cells (MSCs). Here we show that A20 is constitutively expressed in MSCs, which previously has been observed only in cells that are either tumor or immune cells (T/B lymphocytes). TNF $\alpha$ stimulation induced a rapid degradation of A20 protein mediated exclusively by the proteasome in MSCs and not by caspases. This degradation is concomitant to the induction of its own mRNA, which suggests that a tight regulation of NF- $\kappa$ B signaling in MSCs is fundamental. On one hand, we demonstrate that the knockdown of A20-mediated transcript dramatically decreases the adipogenic capacity of MSCs, which correlates with the phenotype observed in the presence of TNF $\alpha$. On the other hand, A20 overexpression blocks NF- $\kappa$ B activation and drives to increased adipogenesis, even in the presence of TNF $\alpha$ treatment. In conclusion, our data demonstrate that the presence of A20 allows MSCs to differentiate into adipocytes by maintaining NF- $\kappa \mathrm{B}$ signaling at a basal state.

Cell Death and Disease (2013) 4, e972; doi:10.1038/cddis.2013.494; published online 19 December 2013

Subject Category: Experimental Medicine

Tumor necrosis factor alpha (TNF $\alpha$ ) is a cytokine involved in several processes in the cell and it has an important role in the regulation of the immune system, apoptosis and inflammation. Dysregulation, and in particular overproduction, of this cytokine has been implicated in a variety of human diseases. ${ }^{1}$ TNF $\alpha$ can activate the nuclear factor kappa-light-chainenhancer of activated $B$ cells $(N F-k B)$ pathway via the TNF $\alpha$ receptor. ${ }^{2}$ There are two known variants of the NF- $\kappa \mathrm{B}$ pathway, the canonical and the non-canonical, although TNF $\alpha$ stimulation is known to trigger mainly the canonical pathway. NF- $\kappa \mathrm{B}$ is inactivated in resting cells by binding to any isoform of $\mathrm{I}_{\kappa} \mathrm{B}$, a family of proteins that prevents signaling by maintaining the NF- $\kappa \mathrm{B}$ dimer in the cytoplasm. In stimulated cells, the $I_{\kappa} \mathrm{B}$ kinase (IKK) complex becomes activated leading to phosphorylation of $\mathrm{I}_{\kappa} \mathrm{B}$ proteins, which are then ubiquitinylated and targeted for degradation by the proteasome. The released transcription factor NF- $\kappa \mathrm{B}$ is subsequently translocated to the nucleus where it regulates the transcriptional activity of a large number of genes. ${ }^{3}$

As for $\mathrm{TNF} \alpha$ signaling, accurate regulation of NF- $\kappa \mathrm{B}$ activity is crucial to prevent a variety of diseases. There are several mechanisms involved in $\mathrm{NF}-\kappa \mathrm{B}$ regulation, including the negative feedback control by which $\mathrm{NF}-\kappa \mathrm{B}$ regulates the transcription of its own inhibitors. Among these inhibitors are the family of $I_{\kappa} B$ and $A 20$, also known as the TNF $\alpha$-induced protein $3 .{ }^{4}$ Although A20 is a ubiquitous protein, it is not constitutively expressed in most cell types with the exception of thymocytes, mature T cells and some tumor cells. ${ }^{5,6}$ In all cell types, A20 transcription is rapidly induced by a large number of stimuli, including $\operatorname{TNF} \alpha,{ }^{7,8}$ that triggers the binding of $\mathrm{NF}-\kappa \mathrm{B}$ to two specific NF- $\kappa \mathrm{B}$-binding sites in the $\mathrm{A} 20$ promoter. ${ }^{4} \mathrm{~A} 20$, in turn, restricts the duration and intensity of $\mathrm{NF}-\kappa \mathrm{B}$ signaling. The first function described for A20 was its cytoprotective effect on TNF stimulation of cells, based on the effect of A20 overexpression. ${ }^{8}$ This was later confirmed genetically as $\mathrm{A2O}^{-/-}$murine embryonic fibroblasts and thymocytes were found to be more sensitive to TNF-induced cell death than wild type cells. ${ }^{5}$ However, the anti-apoptotic function of A20 is not a general feature, as A20 only protects some cell types from specific death inducing agents. The expression, biological activities, and mechanism of action of A20 depend to a large extent on the cellular context. Although a high expression of A20 is often linked to poor prognosis of epithelial malignancies, A20 also functions as a tumor suppressor in several B-cell lymphomas. A20 is composed of two domains, an ovarian tumor (OTU) domain at the $\mathrm{N}$-terminus with deubiquitinase activity and a C-terminal domain built up by seven zinc fingers contributing to its

\footnotetext{
${ }^{1}$ Mesenchymal and Hematopoietic Stem Cell Department, Fundación Inbiomed, Foundation for Stem Cell Research, Paseo Mikeletegi, 81, 20009 San Sebastián, Spain and ${ }^{2}$ Ubiquitylation and Cancer Molecular Biology Laboratory, Fundación Inbiomed, Foundation for Stem Cell Research, Paseo Mikeletegi, 81, 20009 San Sebastián, Spain

${ }^{*}$ Corresponding author: C Trigueros, Mesenchymal and Hematopoietic Stem Cell Laboratory, Fundación Inbiomed, Foundation for Stem Cell Research, Paseo Mikeletegi, 81, 20009 San Sebastián, Spain. Tel: + 34943 309064; Fax: + 34943 308222; E-mail: ctrigueros@ inbiomed.org

${ }^{3}$ These authors contributed equally to this work.

Keywords: A20 inhibitor; mesenchymal stromal cell; adipogenesis

Abbreviations: MSCs, mesenchymal stromal cells; TNF $\alpha$, tumor necrosis factor alpha; NF- $\kappa \mathrm{B}$, nuclear factor kappa-light-chain-enhancer of activated B cells; TNFR,

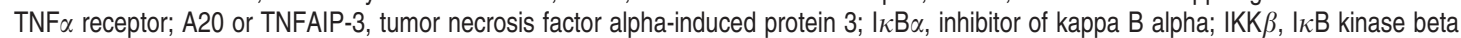

Received 23.7.13; revised 29.10.13; accepted 31.10.13; Edited by R De Maria
} 
ubiquitin ligase activity. This dual ubiquitin-editing capacity of A20 is involved in the inhibition of the NF- $\kappa$ B pathway. ${ }^{9,10}$ In addition, posttranslational modifications of A20 as well as its interaction with ubiquitin binding proteins seem to be critical for its function and activity. ${ }^{11,12}$

Adipose tissue has a fundamental role in the energy homeostasis of the body and the differentiation of preadipocytes to adipocytes is a tightly regulated process. Mature adipocytes are derived from pluripotent mesenchymal stromal cells (MSCs) that have the capacity to develop not only into this cell type but also into chondrocytes and osteocytes. ${ }^{13-15}$ These stem cells reside, among other tissues, in the stroma of the bone marrow and under specific stimuli they undergo a differentiation process in which the progenitor cells become restricted to the adipocyte lineage. Inflammatory cytokines seem to block the adipogenesis of MSCs, ${ }^{16}$ and in fact adipose tissue dysfunctions such as obesity are frequently correlated with elevated levels of TNF $\alpha{ }^{17,18}$ It has been described that TNF $\alpha$ interferes with the homeostasis of adipose tissue in vivo, affecting both the capacity to incorporate fatty acids and to undergo lipolysis as well as the adipogenic process. ${ }^{18}$ In 3T3L1 cells, a mouse embryonic cell line that can differentiate into adipocytes, TNF $\alpha$ has effects on adipocyte gene expression, including suppression of genes essential for insulin responsiveness and selective induction of pre-adipocyte genes. The same study demonstrated that TNF $\alpha$-stimulated NF- $\kappa$ B activation is required for the repression of key adipocyte genes. ${ }^{19}$ Additionally, it has been shown that increased IKK activity promotes insulin resistance in obese mice when the kinase is overexpressed. ${ }^{20}$ Overall, these data clearly demonstrate the relevance of $\mathrm{TNF} \alpha$-induced NF- $\kappa \mathrm{B}$ activation in the homeostasis of the adipose tissue.

In this study we show that the $\mathrm{TNF} \alpha / \mathrm{NF}-\kappa \mathrm{B}$ signaling axis regulates adipogenesis in human bone marrow-derived
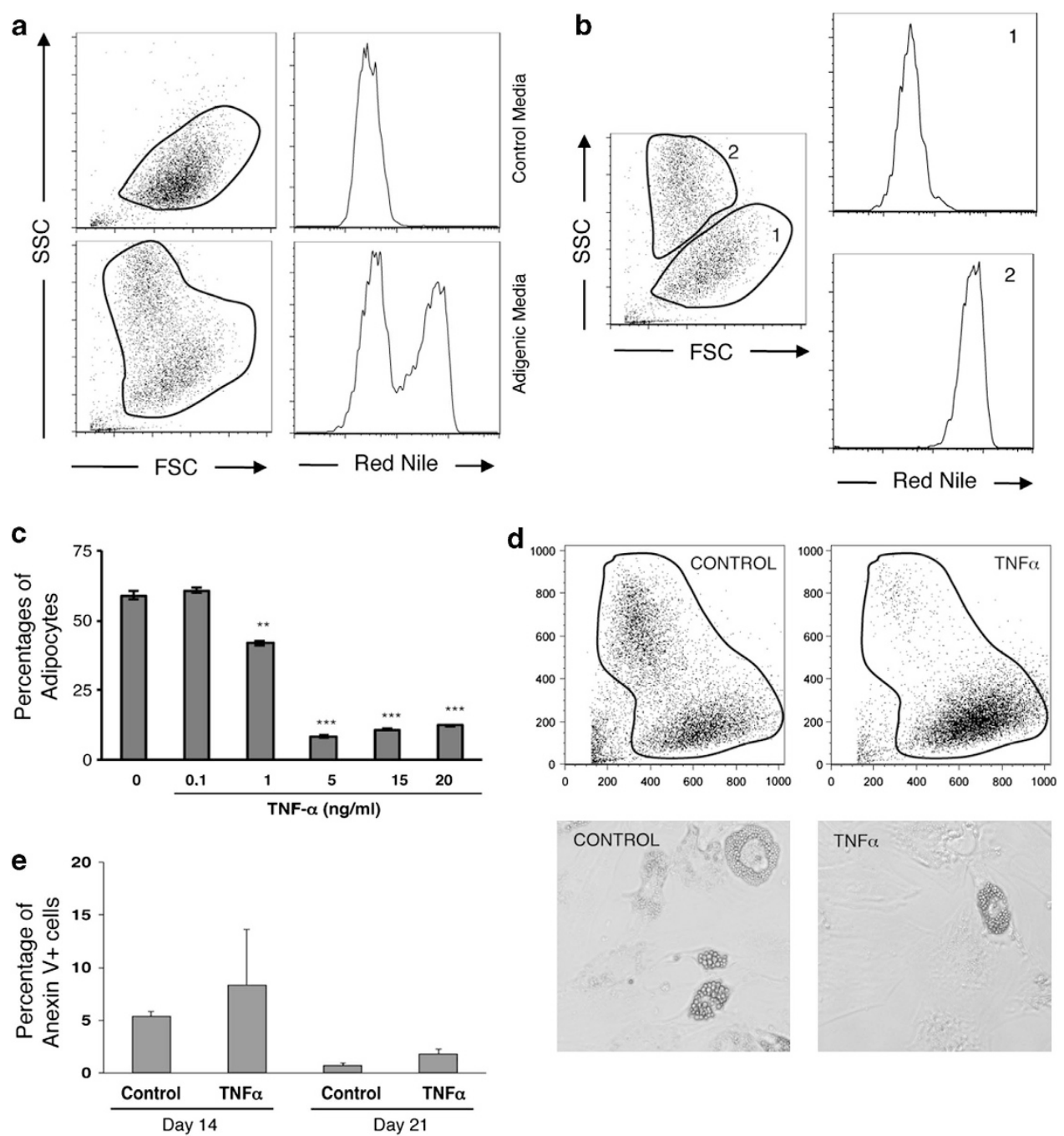

Figure 1 TNF $\alpha$ inhibits adipocytes differentiation from MSCs. (a) Representative staining of lipid droplets by Nile Red. MSCs were induced to differentiate in the absence (control media) or presence of adipogenic medium during 21 days. (b) Side-scatter fluorescence increase correlates with specific fluorescence Nile Red staining (region 1 and 2). (c) MSCs cultured in the presence of increasing concentrations of TNF $\alpha$. Percentages of mature adipocytes were determined by flow cytometry. Results show the mean \pm S.D. of triplicate samples. ${ }^{* *} P<0.01,{ }^{* *} P<0.001$. (d) Representative staining of side-scatter fluorescence in the presence/absence of TNF $\alpha$. Lipid droplet morphology is also shown (400 $\times$ magnification). (e) Analysis of apoptosis in TNF $\alpha$-treated cells induced to differentiate into adipocytes. The percentage of apoptotic cells (Annexin V positive) was measured at 14 and 21-days post-induction by flow cytometry. Results show the means \pm S.D. of triplicate samples 
MSCs. Furthermore, we identify A20 as an important factor in adipocyte differentiation. We demonstrate that A20 is constitutively expressed in human MSCs and that its presence facilitates MSCs differentiation into the adipocyte lineage by the continuous inhibition of the NF- $\kappa$ B pathway. We also show that in MSCs, TNF $\alpha$ stimulation induces a temporary A20 degradation by the proteasome and that this process is indispensable for the regulation of adipogenesis.

\section{Results}

TNF $\alpha$ inhibits adipogenesis in human MSCs through the activation of the NF- $\kappa$ B pathway. In order to improve our understanding of how $\mathrm{TNF} \alpha$ affects adipogenesis via the $\mathrm{NF}-\kappa \mathrm{B}$ pathway in humans, we studied the influence of this cytokine in a human MSCs culture system. As shown in Figure 1a, the adipogenic process results in the appearance of a cell population characterized by an increased intensity of both Nile Red and side-scatter fluorescence, which exhibit a perfect correlation by flow cytometry analysis (Figure 1b). MSCs cultured in the presence of TNF $\alpha$ concentrations ranging from $0-20 \mathrm{ng} / \mathrm{ml}$, show that $\mathrm{TNF} \alpha$ reduces the proportion of adipocytes in a dose-dependent manner (Figure 1c). Indeed, the percentage of adipocytes in culture at the end of the differentiation process decreases from $50-60 \%$ in conditions with no or low concentrations of TNF $\alpha$, to $<10 \%$ with $5-20 \mathrm{ng} / \mathrm{ml} \mathrm{TNF} \alpha$. Mature adipocytes cultured in the presence or absence of $\mathrm{TNF} \alpha$ could not be distinguished in terms of morphology (light microscopy) or complexity of the lipid droplets (side-scatter) (Figure 1d). Analysis of cell death a
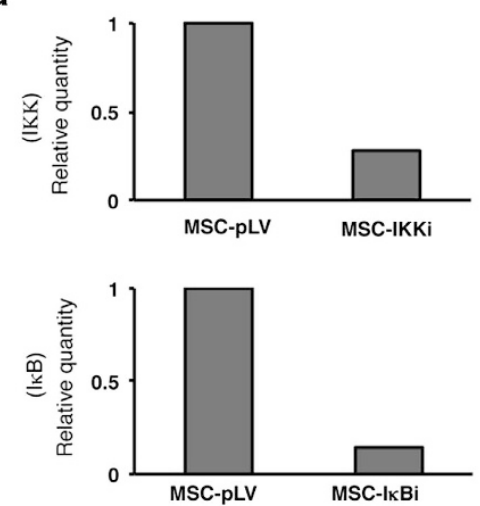

C
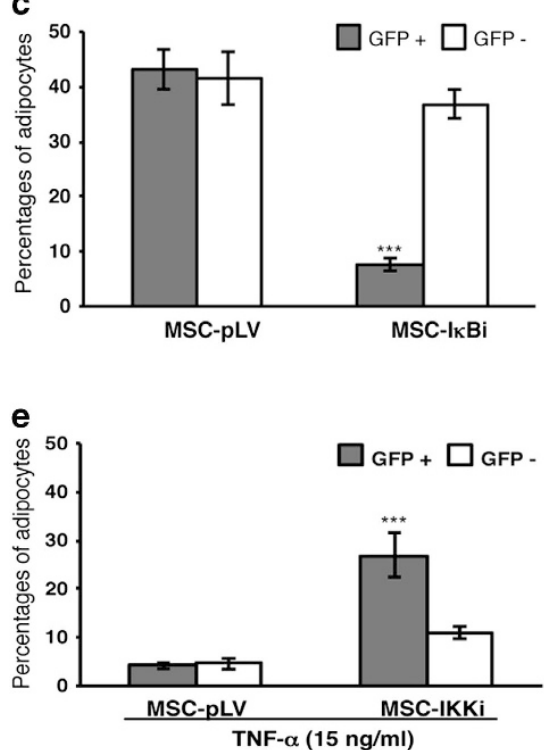

b $\square^{M S C-p L V}$

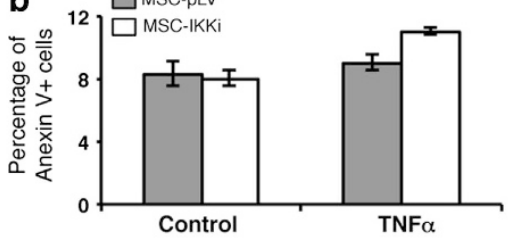

$\square$ MSC-pLV

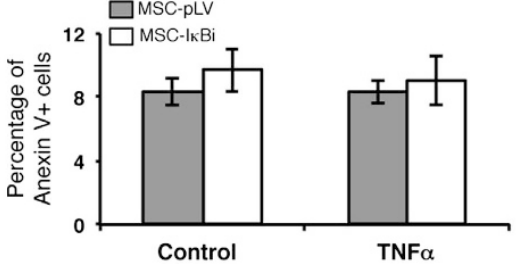

d

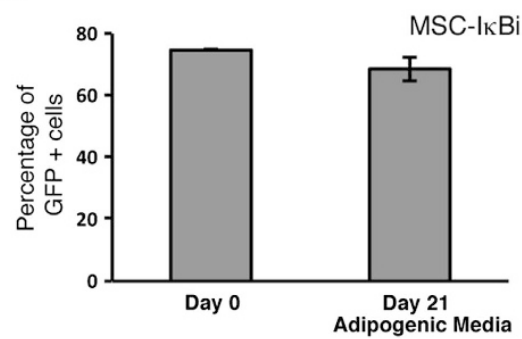

f

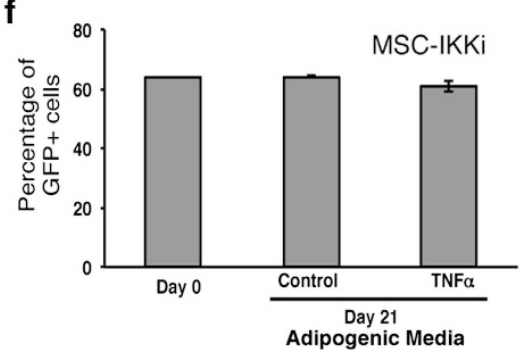

Figure $2 \mathrm{NF}-\kappa \mathrm{B}$ is important for TNF $\alpha$ induced inhibition of adipogenesis in MSCs. (a) IKK $\beta$ and $I_{\kappa} \mathrm{B} \alpha$ expression levels by real-time qPCR in transduced cells. IKK and $I_{\kappa} \mathrm{B} \alpha$ transcripts were 'knocked down' by specific shRNA with more than $80 \%$ efficiency. Relative transcript expression levels were normalized to IKK $\beta$ and $I_{\kappa} \mathrm{B} \alpha$ transcript expression levels from pLV-empty vector infected MSCs, respectively. (b) Analysis of apoptotic cells in IKK $\beta$ (upper panel) and $I_{\kappa} B \alpha$ knockdown cells in the presence/absence of TNF $\alpha$. The percentage of apoptotic cells (Annexin V positive) was measured at 6-days post-infection by flow cytometry. Results show the means \pm S.D. of triplicate samples. (c) $I_{\kappa B} \alpha$ knockdown inhibits adipogenesis capacity in MSCs, which is consistent with the phenotype observed in the presence of TNF $\alpha$, ${ }^{* * *} P<0.001$. (d) Percentage of GFP expression in $I_{\kappa} \mathrm{B} \alpha$ transduced cells before (Day 0) and after (Day 21) adipogenesis differentiation period was analyzed by flow cytometry. (e) IKK $\beta$ knockdown rescues adipogenesis from the inhibition causes by TNF $\alpha$. ${ }^{* \star} P<0.001$. (f) Percentage of GFP expression in IKK $\beta$-transduced cells before (Day 0 ) and after (Day 21) adipogenesis differentiation period in the presence/absence of $15 \mathrm{ng} / \mathrm{ml}$ of TNF $\alpha$ was analyzed by flow cytometry). Results show the means \pm S.D. of triplicate samples 
using Annexin $\mathrm{V}$ staining revealed no significant differences on TNF $\alpha$ stimulation, thus excluding differences in apoptotic rates as a cause for the decreased adipogenesis (Figure 1e). These data taken together with our previous study, where we demonstrated that differentiation of MSCs into adipocytes requires inhibition of cell proliferation, ${ }^{21}$ indicate that TNF $\alpha$ signaling interferes with the adipogenic capacity of MSCs.

Next, we wanted to see how modulating the NF- $\kappa$ B pathway affects the inhibitory effects of TNF $\alpha$ on adipogenesis. This was done by performing the differentiation process in the presence or absence of TNF $\alpha$ in MSCs in which inhibitor of kappa $\mathrm{B}$ alpha $\left(\mathrm{I}_{\kappa} \mathrm{B} \alpha\right)$ or $\mathrm{IKK} \beta$ transcripts were silenced. A GFP-expressing lentiviral vector (pLVTHM) was used to transduce human MSCs at various multiplicities of infection with a stable $\mid \kappa \mathrm{B} \alpha$ or $\mathrm{IKK} \beta$-specific shRNA. As shown in Figure $1 \mathrm{~b}$, shRNA-transduced MSCs (MSC- $\mathrm{I}_{\kappa} \mathrm{Bi}$ or MSC$\mathrm{IKK} \beta \mathrm{i}$ ) resulted in efficient reduction of the $\mathrm{I}_{\kappa} \mathrm{B} \alpha$ and $\mathrm{IKK} \beta$ expression, respectively (Figure $2 \mathrm{a}$ ). It is important to mention that the absence of either transcripts did not correlate with increased cell death, and this effect is independent of TNF $\alpha$ treatment (Figure 2b). We observed that knocking down of $\mathrm{I} \kappa \mathrm{B} \alpha$ resulted in almost fivefold fewer adipocytes in transduced $\left(\mathrm{GFP}^{+}\right)$MSCs compared with empty $\mathrm{GFP}^{+}$control cells after induction of the differentiation process (Figure $2 \mathrm{c}$ ). Thus, silencing $\mid \kappa \mathrm{B} \alpha$ showed similar effects as those observed in presence of TNF $\alpha$. In contrast, no significant effects are observed in cells knocked down for $\mathrm{IKK} \beta$ in the absence of TNF $\alpha$ (data not shown). However, the addition of TNF $\alpha$ to the MSCs-IKK $\beta$ i culture results in a decrease of adipogenesis in GFP $^{-}$cells similar to the control cells, whereas the adipogenesis in $\mathrm{GFP}^{+}$cells is only partially affected (Figure 2e). Importantly, MSCs infected with the $\mathrm{I}_{\kappa} \mathrm{Bi}$ or IKK $\beta \mathrm{i}$ $\left( \pm \mathrm{TNF} \alpha\right.$ ) vector maintain the same ratio between $\mathrm{GFP}^{+}$and $\mathrm{GFP}^{-}$cells during the whole differentiation process (21 days), suggesting that the knockdown of both transcripts has no effect on cell death (Figures $2 d$ and $f$, respectively).
In conclusion, these results show that the effect of TNF $\alpha$ on the adipogenic potential of human MSCs is mainly due to the activation of the NF- $\kappa$ B pathway by this cytokine.

A20 is constitutively expressed in MSCs. As A20 is one of the main inhibitors of $\mathrm{NF}-\kappa \mathrm{B}$ and modulation of this pathway significantly affects the adipogenesis, we checked A20 expression in MSCs by RT qPCR and western blot. Contrary to what is found in most cell types, the expression analysis by RT qPCR reveals that A20 is highly expressed in MSCs. Only low levels of A20 could be observed in 293Ts and human skin fibroblasts (Figures $3 a$ and b). We checked this unexpected result by measuring protein levels in MSCs from three different healthy donors by western blot. Figure $3 b$ shows that $A 20$ protein was only detectable in those samples from MSCs, whereas very low or undetectable protein levels were found in $293 \mathrm{~T}$ and fibroblast. So far, constitutive expression of A20 has only been described in certain cells of the immune system and some tumor cell lines. ${ }^{11}$ The adipogenic stimulation gave rise to an important reduction of $\mathrm{A} 20$ expression, although we could still detect its expression during the whole culture period (day 7, 14 and 21, Figure 3c). Next, we wanted to know if the constitutive expression of $\mathrm{A} 20$ was due to the activity of $\mathrm{NF}-\kappa \mathrm{B}$. We used the 'knock down' of $\mathrm{IKK} \beta$ and $\mathrm{I}_{\kappa} \mathrm{B} \alpha$ in MSCs to find out if modulation of the NF- $\kappa \mathrm{B}$ pathway activity influenced the expression of A20. A20 expression was again quantified using RT qPCR. In MSCs where IKK $\beta$ had been silenced (MSC-IKK $\beta \mathrm{i}$ ), and thus the NF- $\kappa \mathrm{B}$ activity is abolished, a reduction of the A20 mRNA expression could be observed (Figure $3 d$ ). On the contrary, MSCs transduced with the hairpin targeting $\mathrm{I}_{\kappa} \mathrm{B} \alpha$, displayed an increased A20 expression (Figure 3d). As there are no changes in A20 expression in MSCs transduced with the empty vector (MSC-pLV), this data demonstrate that the constant expression of A20 in these cells is dependent on the NF- $\kappa \mathrm{B}$ activity.

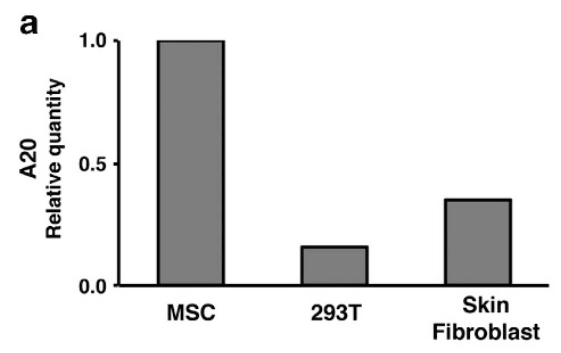

c

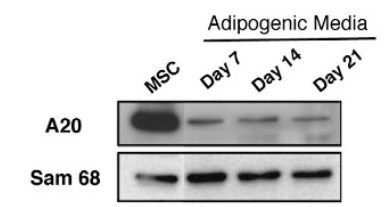

b
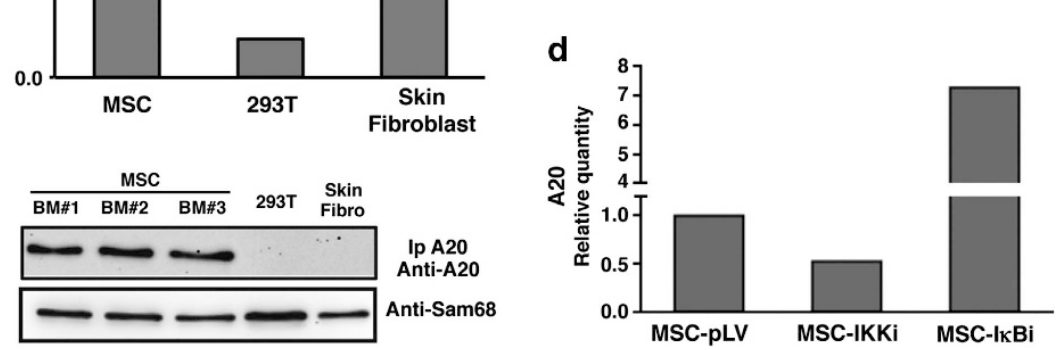

Figure 3 A20 protein is expressed constitutively in human MSCs. (a) A20 expression levels by real-time qPCR in MSCs, fibroblast and 293 T cells. Relative transcript expression levels were normalized to A20 transcript expression levels to human MSCs. (b) A20 protein analysis in three independent human bone marrow MSCs. Samples were compared with primary fibroblast from human skin and $293 \mathrm{~T}$ cell line. A20 protein expression level was measured by western blot using extracts where A20 was immunoprecipitated. (c) A20 expression during the differentiation process. A20 expression levels were measured by western blot in total cell extracts using the antibody for A20. Sam68 was used as a loading control (d) A20 expression is dependent of NF- $\kappa$ B activation. IKK $\beta$ (MSC-IKKi) and $I_{\kappa} B \alpha$ (MSC- $I_{\kappa} B i$ ) transcripts were 'knocked down' by specific shRNA. Six-days post-infection MSCs were analyzed for A20 expression levels by real-time qPCR. Relative transcript expression levels were normalized to MSCs transduced with the empty vector (MSC-pLV) 
TNF $\alpha$ induces degradation of A20 by the proteasome in MSCs. Intrigued by the finding that A20 is constitutively expressed in MSCs, we investigated how the expression of this protein was influenced by TNF $\alpha$ in these cells. Therefore, a time course experiment quantifying A20 protein and mRNA levels in MSCs treated with TNF $\alpha$ was performed. To our surprise, the protein analysis revealed that the stimulation with TNF $\alpha$ does not induce an increase of A20 expression as in most cells but rather a rapid and temporal decrease of the A20 level is observed (Figure 4a). Besides, the quantification of mRNA showed that TNF $\alpha$ rapidly induces an increase in the A20 mRNA expression and maintains the levels during the whole time of the experiment (Figure 4b). A similar decrease of $\mathrm{A} 20$ levels can also be observed on T-cell receptor (TCR) stimulation with CD3/CD28 in $T$ cells. This decrease depends mainly on the paracaspase

a
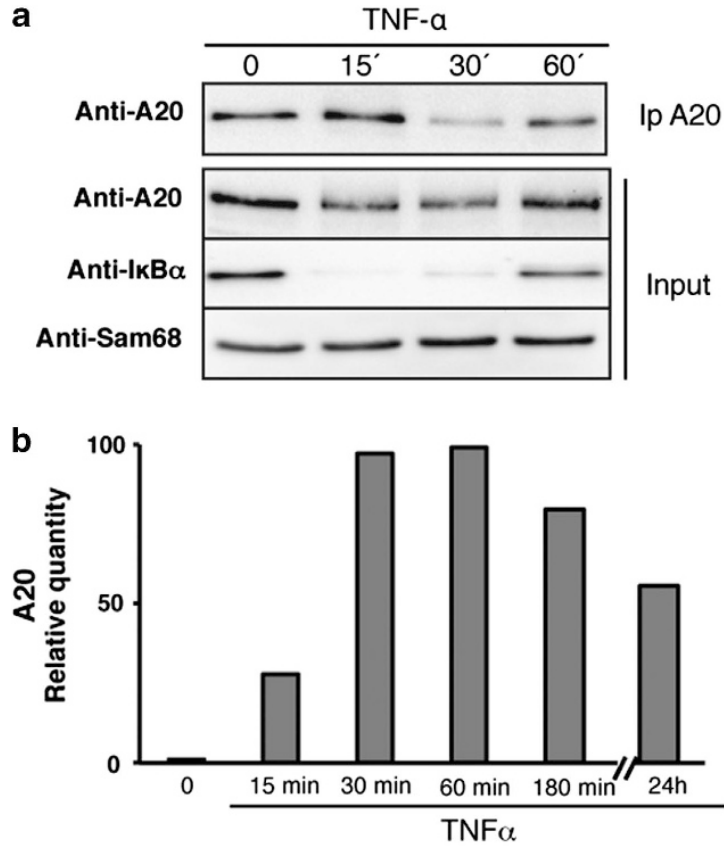

C

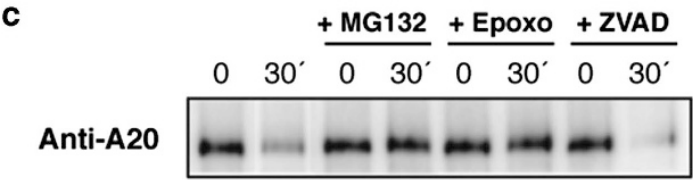

TNF-a Ip A20

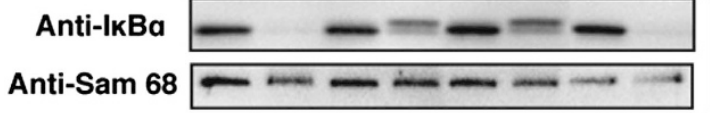

Input

Figure $4 \mathrm{TNF} \alpha$ induced A20 degradation is dependent of the proteasome in MSCs. (a) TNF $\alpha$ stimulation induced a degradation of A20 in MSCs. Cells were stimulated with $\mathrm{TNF} \alpha$ for the indicated time, and lysates were submitted to A2O immunoprecipitation to detect the level of the protein by western blot. (b) A20 expression levels by real-time qPCR in MSCs stimulated with TNF $\alpha$ for the indicated time. Relative transcript expression levels were normalized to A20 transcript expression levels to non TNF $\alpha$-treated human MSCs. (c) TNF $\alpha$-induced A20 degradation is dependent of the proteasome. Before stimulation with TNF $\alpha$ for the indicated time, cells were pretreated with inhibitors of the proteasome (MG132 or epoxomicin) or inhibitor of caspase (ZVAD). Lysates were submitted to an A20 immunoprecipitation to check the level of A20 in each condition mucosa-associated lymphoid tissue lymphoma translocation protein 1 (MALT-1), which induces a cleavage of A20 and therefore an activation of $\mathrm{NF}-\kappa \mathrm{B}$ pathway. ${ }^{22}$ Other studies suggest that the implication of the proteasome as well in the reduction of $\mathrm{A} 20$ induced after TCR stimulation. ${ }^{23}$ In order to determine the mechanism involved in the decrease of A20 in MSCs, the cells were treated with proteasome inhibitors (MG-132 or epoxomycin) or a generic caspase inhibitor (Benzyloxycarbonyl-Val-Ala-Asp (OMe)-fluoromethyl ketone, ZVAD) before TNF $\alpha$ stimulation. The levels of A20 quantified by western blot show that inhibition of the proteasome, but not of caspases, impedes A20 degradation (Figure 4c). These results indicate that stimulation of MSCs with TNF $\alpha$ provokes the temporal degradation of A20 by the proteasome at the same time as it induces de novo transcription through the activation of the NF- $\kappa \mathrm{B}$ pathway. Interestingly, the regulation of $\mathrm{A} 20$ expression after $\mathrm{TNF} \alpha$ stimulation in MSCs clearly resembles the one observed for $\mathrm{I}_{\kappa} \mathrm{B} \alpha$, although with different kinetics.

Modification of A20 expression in MSCs affects adipogenesis. As the level of NF- $\kappa$ B activity influences adipocyte differentiation and human MSCs show a constitutive expression of $\mathrm{A} 20$, we next determined the role of $\mathrm{A} 20$ in this process. We tested MSCs differentiation in adipogenic conditions after modulating A20 levels with vectors carrying either A20 cDNA (MSC-pRRL-A20) or A20 specific shRNA (MSC-pLV-A20i). As shown in Figure 5a, A20 is clearly reduced as verified by western blot when MSCs are transduced ( $>95 \%$ efficiency) with pLV-A20i vector. To provide further evidence of A20 implication, we measured the induction of IL-6 expression as an indicator of NF- $\kappa \mathrm{B}$ activation. $^{24}$ The reduction in A20 expression led to an expected increase of $\mathrm{NF}-\kappa \mathrm{B}$ activation and resulted in a marked upregulation of IL-6 expression in MSCs transduced with pLV-A20i vector (Figure 5b). Subsequently, the effect of reduced $\mathrm{A} 20$ levels on adipogenesis was investigated by analysis of $\mathrm{GFP}^{+}$and GFP ${ }^{-}$in MSCs transduced ( $\sim 50 \%$ ) with the empty or A20i vectors. Results show that the percentage of adipocytes in GFP ${ }^{+}$MSCs, in which A20 has been silenced, is significantly lower than in $\mathrm{GFP}^{-}$cells, whereas cells transduced with the empty vector maintained a comparable level of adipogenesis as non-transduced control cells in the same cultures (Figure $5 \mathrm{c}$ ).

In contrast to its well established role in repressing NF- $\kappa \mathrm{B}$ activation, the anti-apoptotic activity of A20 remains controversial and appears to be specific to cell type and stimulus. $^{7,25-27}$ For this reason, we decided to check if the A20 silencing could induce apoptosis in MSCs. As shown in Figure $5 d$, the inhibition of A20 expression did not correlate with increased percentages of apoptotic cells (MSC-A20i) compared with MSCs transduced with the empty vector (MSC-pLV). This result demonstrates that the impairment of adipogenesis after A20 silencing is not due to increased apoptosis, thus suggesting that it is a result of direct interference with the adipogenic process.

On the other hand, pRRL-A20-transduced cells overexpressed A20 protein (Figure 6a), correlated with a decrease in IL-6 mRNA levels even in the presence of TNF $\alpha$ when compared with cells transduced with the empty vector (Figure 6b). 

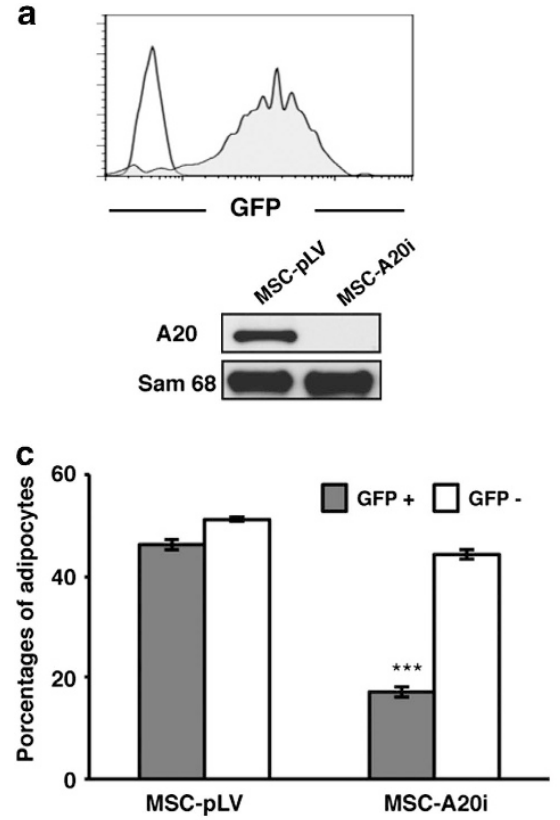

b
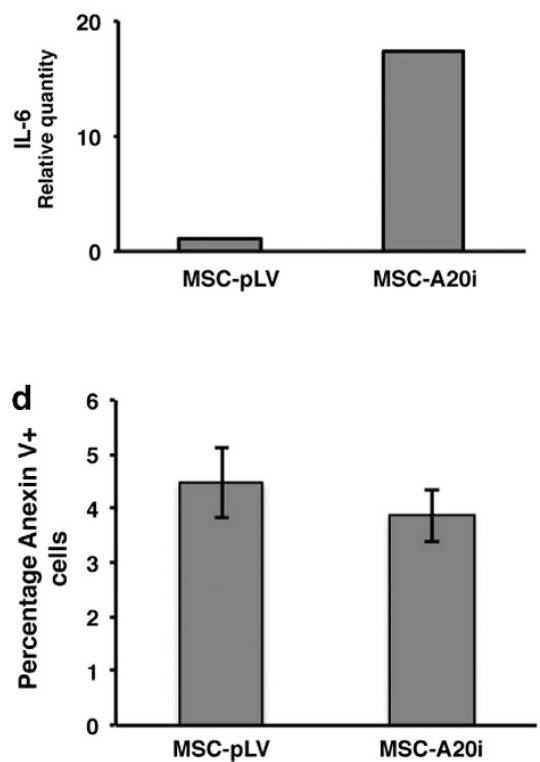

Figure 5 A20 is essential for the adipogenic capacity of human MSCs. (a) A20 specific gene silencing by lentivirus-mediated shRNA. Four-days transduced MSCs were collected and GFP expression was analyzed by flow cytometry (gray). Negative control: non-infected MSCs (white). Western blot analysis of A20 expression after specific knock down (MSC-A20i). Protein expression levels were analyzed in total cell extracts. MSCs transduced with the empty vector were used to compare the efficiency from the specific shRNA (MSC-pLV). Sam68 was used as a loading control. (b) Quantification by real-time qPCR of IL-6 after 6 days of culture in MSCs transduced with the empty vector or with the specific A20 shRNA. (c) A20 knockdown induced an inhibition of adipogenesis in MSCs. MSCs showing $\sim 50 \%$ infection efficiency with either empty vector (MSC-pLV) or pLV-specific shRNA (MSC-A20i) containing vectors were induced to adipogenic differentiation. Percentages of adipocytes were determined by flow cytometry. Results show the means \pm S.D. of triplicate samples. ${ }^{* *} P<0.001$. (d) Analysis of apoptotis in cells where A20 expression was knocked down. The percentage of apoptotic cells (annexin V positive) was measured at 7-days post-infection by flow cytometry (GFP positive). Necrotic cells were discarded by specific TO-PRO-3 staining. Results show the means of triplicate samples

These data clearly demonstrate the reduction of NF- $\kappa \mathrm{B}$ activity in MSCs overexpressing A20. To determine how A20 overexpression influences adipocyte differentiation in human MSCs we compared non-infected cells $\left(\mathrm{GFP}^{-}\right)$with cell transduced with either the empty or A20 expression vector $\left(\mathrm{GFP}^{+}\right)$in the presence or absence of TNF $\alpha$. As shown in Figure $6 \mathrm{c}$, cells transduced with the empty vector $\left(\mathrm{GFP}^{+}\right)$ generated the same percentages of adipocytes than noninfected cells $\left(\mathrm{GFP}^{-}\right)$indicating no effect from the viral integrations. More important, there was a significant increase in adipocytes from cell overexpressing A20 $\left(\mathrm{GFP}^{+}\right) \mathrm{com}-$ pared with cells transduced with the empty vector $(>20 \%)$. This shows that the overexpression of A20 results in a more efficient adipogenesis. Interestingly, the presence of TNF $\alpha$ that inhibited the adipogenesis in cell transduced with the empty vector was partially but significantly reverted in cells overexpressing A20 (Figure 6c), demonstrating that A20 counteracts the activation of NF- $\kappa$ B induced by TNF $\alpha$. Taken together, these results clearly show that the A20 has an important role in the regulation of the adipogenic capacity in human MSCs.

\section{Discussion}

In this report, we have studied the effect of TNF $\alpha$ on adipogenesis in human MSCs and the mechanisms behind. Adipogenesis is a tightly regulated process initiated by the sequential activation of CCAAT/enhancer binding proteins
(C/EBPs) and peroxisome proliferator-activated receptor $\gamma$ (PPAR $\gamma$ ). C/EBP $\beta$ and C/EBP $\delta$ are transiently induced by CAMP and glucocorticoids and lead to the expression of the main adipogenic transcription regulators $\mathrm{C} / \mathrm{EBP} \alpha$ and PPAR $\gamma$. These two transcription factors then orchestrate a large number of genes involved in the progression of the differentiation process. TNF $\alpha$ is known to interfere with the adipogenesis via inhibition of C/EBP and PPAR $\gamma$ activity, which will negatively influence the adipogenesis. A number of signals downstream of TNF $\alpha$ have been linked to the suppression of the activity of both transcription factors. These include activation of ERK, JNK, IKK $\beta$ and ceramide synthesis. ${ }^{18,28-30}$ However, in this study we demonstrate that TNF $\alpha$ also interferes with adipogenesis via the influence of NF- $\kappa$ B activation, and in particular of A20 activity. The lack of an inhibitor-dependent regulatory circuit (A20 knockdown) leads to prolonged NF- $\kappa$ B signaling in MSCs, which drives to limited adipogenic capacity. Vice versa, permanent interruption of the NF- $\kappa$ B signaling pathway by A20 overexpression produces an increase in the generation of adipocytes. These data clearly demonstrate that the presence of A20 exerts a pro-adipogenic effect in human MSCs. This previously unknown mechanism provides another factor in the complex process of adipogenesis. However, further analysis is necessary in order to elucidate the relationship between $\mathrm{A} 20$ and the main transcription factors (PPAR and c/EBP) involved in this differentiation pathway in MSCs. 
a

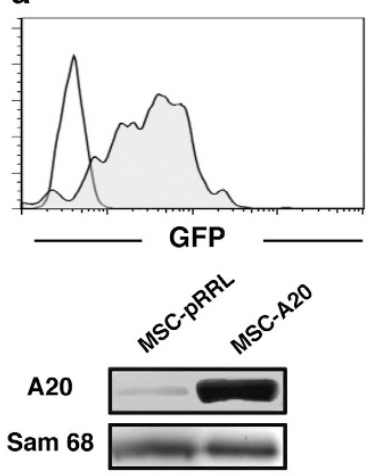

b

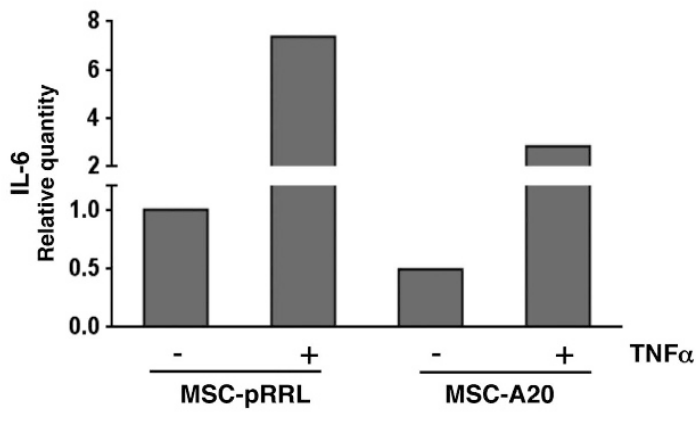

C

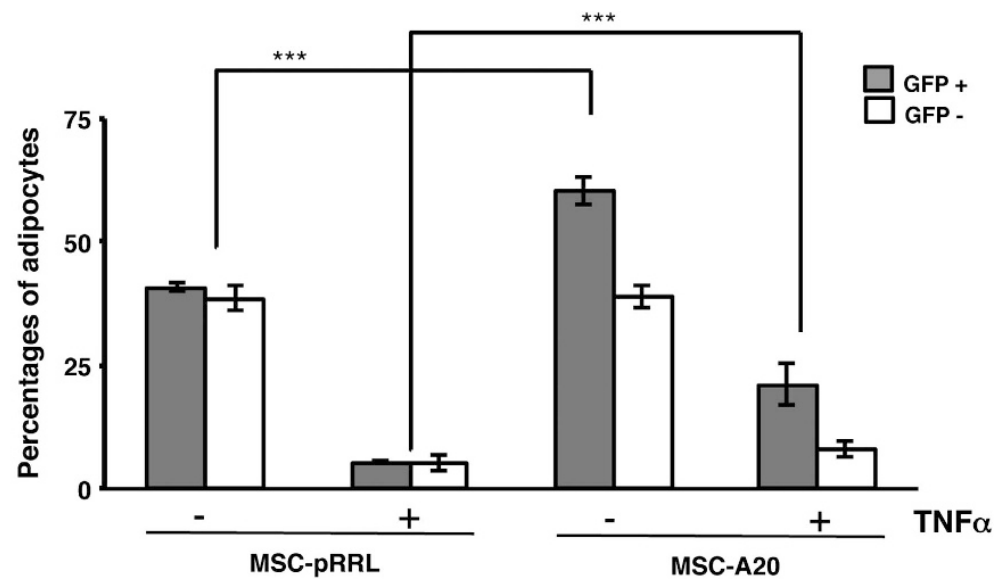

Figure 6 A20 overexpression stimulates the adipogenic capacity of human MSCs. (a) MSCs were transduced with the empty bicistronic expression vector pRRL (MSCpRRL) or containing the A20 CDNA (MSC-A20). Transduction efficiency was analyzed by flow cytometry (GFP ${ }^{+}$cells). A20 overexpression was determined by western blot in total cell extracts. Sam68 was used as a loading control. (b) Quantification by real-time qPCR of IL-6. MSCs overexpressing A20 transcript for 4 days were cultured for additional $24 \mathrm{~h}$ in the presence or absence of $15 \mathrm{ng} / \mathrm{ml} \mathrm{TNF} \alpha$. Relative transcript IL-6 expression levels were normalized to MSCs transduced with the empty vector cultured in the absence of TNF $\alpha$. (c) MSCs differentiation capacity is influenced by A20 overexpression. MSCs showing $\sim 50 \%$ infection efficiency were induced to differentiate into adipocytes in the presence or absence of TNF $\alpha$. Percentages of mature adipocytes from GFP ${ }^{-}$(white bars) and GFP ${ }^{+}$(gray bars) cells (with the empty vector or A20-cDNA expressing vector, respectively) after the induction period are represented. Results show the mean \pm S.D. of triplicates samples. ${ }^{* \star *} P<0.001$

Surprisingly, we have found that A20, an important negative regulator of $\mathrm{NF}-\kappa \mathrm{B}$ signaling, is constitutively expressed in MSCs. To our knowledge, this is the first time that constitutive expression of $\mathrm{A} 20$ is observed in cells that are neither tumoral nor related to the immune system. In most cell types A20 is absent or expressed at very low basal levels; multiple NF- $\kappa \mathrm{B}$ activating stimuli quickly induce $\mathrm{A} 20$ expression via NF- $\kappa \mathrm{B}$ sites in the $\mathrm{A} 20$ promoter. It is believed that $\mathrm{A} 20$ acts as a negative regulator that balances the strength and duration of $\mathrm{NF}-\kappa \mathrm{B}$ activation. In T cells, on the other hand, A20 is highly expressed at basal state and is reduced on stimulation of the TCR. The constitutive expression of A20 in lymphocytes can be understood as a security system to avoid the severe consequences of an uncontrolled NF- $\kappa$ B activation and where A20 is employed as a brake to prevent unspecific activation of the pathway. ${ }^{23}$ In short, TCR stimulation triggers the cleavage of $A 20$ by MALT-1, which impairs the inhibitory function of $A 20$ and adjust the $\mathrm{NF}-\kappa \mathrm{B}$ signaling in the $\mathrm{T}$ cell. ${ }^{22} \mathrm{An}$ analogous regulation of NF- $\kappa B$ signaling seems to exist in B cells. ${ }^{31}$ The constitutive expression of A20 in MSCs is obviously regulated in a different manner than in lymphocytes. Our results demonstrate that the stimulation with $\mathrm{TNF} \alpha$ induces proteasomal degradation of A20 in MSCs, a regulatory mechanism of A20 that has not been observed previously. We could not observe any effect on the efficiency of TNF $\alpha$ induced A20 degradation after addition of caspase inhibitor, although inhibition of the proteasome prevented the decrease in A20 levels. Thus, in contrary to what is observed in lymphocytes after TCR stimulation where A20 expression is regulated mainly by MALT-1, and to a lesser extent by the proteasome, the degradation in MSCs is induced by TNF $\alpha$ and performed by the proteasome. A20 degradation observed after TNF $\alpha$ stimulation is accompanied by induction of transcription of its own mRNA due to NF- $\kappa$ B activation, which suggests that a tight regulation of $\mathrm{NF}-\kappa \mathrm{B}$ signaling in MSCs is fundamental. A complete molecular study of A20 in MSCs could help to understand all the functions and regulation mechanism of this protein, since at least its expression and degradation in those cells are different.

The consequences of NF- $\kappa \mathrm{B}$ activity are diverse, depending both on the cell type and on the stimuli received by the cell. A complex network of regulatory mechanisms acts on several levels of the pathway in order to achieve the correct response. In the same way, A20 depends on various adaptor and 
effector molecules to inhibit NF- $\kappa \mathrm{B}$, and thus functions differently depending on the cell type or received stimuli. Clearly, the inhibitory function of $\mathrm{A} 20$ on NF- $\kappa \mathrm{B}$ signaling is different in MSCs than in most other cells, as A20 is constitutively expressed and its level after stimulation is differently regulated. In this sense, this study demonstrates for the first time that $\mathrm{A} 20$ exerts a protective role on MSCs by influencing the adipogenic differentiation in the presence of inflammatory cytokines.

\section{Materials and Methods \\ Cell culture. Human bone marrow-derived MSCs were obtained from the Inbiobank Stem Cell Bank (www.inbiobank.org) as previously described. ${ }^{21}$ Briefly, cadaveric bone marrow was collected from brain-dead donors after informed consent and under the Spanish National Organization of Transplant supervision (Organización Nacional de Transplantes, ONT). Generated MSCs display a typical $\mathrm{CD}_{2}{ }^{+}, \mathrm{CD}_{3}{ }^{+}, \mathrm{CD} 0^{+}, \mathrm{CD} 105^{+}, \mathrm{CD}_{166}{ }^{+}, \mathrm{CD} 146^{+}, \mathrm{CD} 34^{-}, \mathrm{CD} 45^{-}$, $\mathrm{CD} 14^{-}, \mathrm{CD} 19^{-}$, and $\mathrm{CD} 31^{-}$phenotype- a fibroblast-like morphology- and at least trilineage potential, including osteocyte, chondrocyte, and adipocyte generation. ${ }^{21}$ MSCs were cultured in low-glucose DMEM supplemented with $10 \%$ FBS, $2 \mathrm{mM}$ glutamine, $100 \mathrm{U} / \mathrm{ml}$ penicillin and $0.1 \mathrm{mg} / \mathrm{ml}$ streptomycin (all from Sigma-Aldrich, St Louis, MO, USA). On reaching confluence, MSCs were trypsinized and seeded at a density of $1 \times 10^{3} \mathrm{cells} / \mathrm{cm}^{2}$. Cells were obtained at passage three from the Stem Cell Bank. All experiments were carried out with cultures of low passage (passage number four to eight). $293 \mathrm{~T}$ cells were obtained from ATCC (www.atcc.org) and cultured in high-glucose DMEM supplemented with $10 \% \mathrm{FBS}, 2 \mathrm{mM}$ glutamine, $100 \mathrm{U} / \mathrm{ml}$ and $0.1 \mathrm{mg} / \mathrm{ml}$ streptomycin. Fibroblasts were obtained from the Inbiobank Stem Cell Bank (www.inbiobank.org), and cultured in high-glucose DMEM supplemented with $10 \%$ FBS, 2 mM glutamine, $100 \mathrm{U} / \mathrm{ml}$ and $0.1 \mathrm{mg} / \mathrm{ml}$ streptomycin.}

Gene silencing. shRNA expression vectors were constructed using standard cloning procedures. The shRNA sequences have been published previously and were purchased from Sigma-Genosys (St. Louis, MO, USA); A20i, AGTTGGATGA AGCTAACTTAC (The RNAi Consortium, www.broadinstitute.org/rnai/trc); IKK $\beta \mathrm{i}$, GGAAGTACCTGAACCAGTTTG; I $\kappa$ Bi, GAGTCAGAGTTCACGGAGTTC. Oligonucleotides were annealed and cloned into pSUPER plasmid carrying a $\mathrm{H} 1$ promoter using Bglll-HindllI sites. The H1-shRNA expression cassette was then excised and cloned into pLVTHM (Addgene plasmid 12247, www.addgene.org) using EcoRI-Clal sites. Viral particles were produced as previously described by the Viral Vector Platform at the Inbiomed Foundation. ${ }^{21}$ MSCs transduction was carried out at a multiplicity of infection of four in order to achieve $50 \%$ infection and ten in order to achieve $100 \%$ infection.

Gene overexpression. A20 was amplified from cDNA of purified T cells using the following primers $5^{\prime}$ ACAAACGAATTCATGGCTGAAGTCCTTC $3^{\prime}$ and 5'GCCGAGGAATTCTTAGGGGCA-GTTGGGCGTTTC3' and cloned into pcDNA3 to obtain pcDNA3-A20. A20 was then subcloned into lentiviral vector $P R R L$.

RT qPCR. Total RNA was extracted using the RNAeasy extraction kit (Qiagen, Valencia, CA, USA). cDNA was obtained using the GeneAmp RNA PCR Core kit (Applied Biosystems, Carlsbad, CA, USA, N8080143G), following the manufacturer's instructions. Quantitative PCRs were performed on these cDNAs using Power SYBR Green PCR Master Mix (Applied Biosystems, 4367659). A20, IL-6, $\mid \kappa B \alpha$ and GAPDH were amplified using the following oligonucleotide pairs: $A 20$, GTCCGGAAGCTTGTGGCGCT and CCAAGTCTGTGTCCTGAACGCCC (97 bp); IL-6, CCAGGAGCCCAGCTATGAAC and GAGCAGCCCCAGGGAGAA (71 bp); $1 \kappa \mathrm{B} \alpha$, GATCCGCCAGGTGAAGGG and GCAATTTCTGGCTGGTTGG (102 bp); and GAPDH, TGCACCACCAACTGCTTAGC and GGCATGGACTGTGGTCATG AG (87 bp, Vandesompele et al., 2002). Reactions were carried out in a Thermocycler Step One Plus (Applied Biosystems). Data were compared using the $\Delta \Delta \mathrm{C}_{\mathrm{T}}$ method. GAPDH was used as a housekeeping gene control.

Adipocyte differentiation. MSCs were seeded at a density of 25000 cells per $\mathrm{cm}^{2}$ in low-glucose DMEM medium supplemented with $10 \% \mathrm{FBS}, 2 \mathrm{mM}$ glutamine, $100 \mathrm{U} / \mathrm{ml}$ penicillin and $0.1 \mathrm{mg} / \mathrm{ml}$ streptomycin (all from Sigma-Aldrich). Once the cells had adhered (after 18-24h) the medium was exchanged for fresh medium supplemented with $1 \mu \mathrm{M}$ dexamethasone (Sigma-Aldrich, D4902), $200 \mu \mathrm{M}$ indomethacin (Sigma-Aldrich, 17378), $500 \mu \mathrm{M}$ 3-isobutyl-1-methylxanthine (IBMX, Sigma-Aldrich, I5879) and when indicated with TNF $\alpha$ (R\&D, Minneapolis, MN, USA, 210-TA). The differentiation medium was refreshed every 2-3 days until the end of the experiment at day 21. Once the differentiation was completed the percentage of adipocytes in the culture was determined by flow cytometry. Briefly, cells were trypsinized and washed with PBS. After fixation ( $0.5 \%$ paraformaldehyde) for $15 \mathrm{~min}$, cells were stained with $1 \mathrm{mg} / \mathrm{ml}$ Nile Red (Sigma-Aldrich) for $30 \mathrm{~min}$ on ice. ${ }^{32}$

Protein analysis. For western blots, $10^{5}$ cells were lysed for $30 \mathrm{~min}$ on ice in $50 \mathrm{mM}$ sodium fluoride, $5 \mathrm{mM}$ tetra-sodium pyrophosphate, $10 \mathrm{mM}$ betaglyceropyrophosphate, 1\% Igepal CA-630, 2 mM EDTA, $20 \mathrm{mM} \mathrm{Na}_{2} \mathrm{HPO}_{4}, 20 \mathrm{mM}$ $\mathrm{NaH}_{2} \mathrm{PO}_{4}$ and $1.2 \mathrm{mg} / \mathrm{ml}$ complete protease inhibitor cocktail (Roche, Indianapolis, IN, USA). When indicated, cells were treated with MG132 (Sigma-Aldrich, $20 \mu \mathrm{M}$ ), Epoxomicin (Enzo Life Sciences, Farmingdale, NY, USA, $50 \mu \mathrm{M}$ ) or ZVAD (Enzo Life Sciences, $100 \mu \mathrm{M}$ ) before TNF $\alpha$ (R\&D, $15 \mathrm{ng} / \mathrm{ml})$ stimulation, and lysed as previously described.

Immunoprecipitation experiments were performed using Protein-G cross-linked with the anti-A20 antibody. Western blot analysis was performed with the following primary antibodies: mouse monoclonal anti-human $\mid \kappa B \alpha$ (Cell Signalling Technology, Beverly, MA, USA) and anti-human A20 (Calbiochem, La Jolla, CA, USA) antibodies, and rabbit polyclonal anti-human Sam68 antibody (Santa Cruz Biotechnology, Santa Cruz, CA, USA).

\section{Conflict of Interest}

The authors declare no conflict of interests.

Acknowledgements. We would like to thank Pilar Olaizola of Hospital Donostia for Technical support in Inbiobank. This work was supported by the 'Obra Social KUTXA', Ministerio de Economía y Competitividad (FIS PI12/01982), the Basque Country Government and the Diputación Foral de Guipúzcoa. Valerie Lang was supported by the Ramón y Cajal Program, Ministerio de Economía y Competitividad grant BFU2006-12991.

1. Locksley RM, Killeen N, Lenardo MJ. The TNF and TNF receptor superfamilies: integrating mammalian biology. Cell 2001; 104: 487-501.

2. Silke J. The regulation of TNF signalling: what a tangled web we weave. Curr Opin Immunol 2011; 23: 620-626.

3. Hayden MS, Ghosh S. Shared principles in NF-kappaB signaling. Cell 2008; 132: 344-362.

4. Krikos A, Laherty CD, Dixit VM. Transcriptional activation of the tumor necrosis factor alpha-inducible zinc finger protein, A20, is mediated by kappa B elements. J Biol Chem 1992; 267: 17971-17976.

5. Lee EG, Boone DL, Chai S, Libby SL, Chien M, Lodolce JP et al. Failure to regulate TNFinduced NF-kappaB and cell death responses in A20-deficient mice. Science 2000; 289: 2350-2354.

6. Tewari M, Wolf FW, Seldin MF, O'Shea KS, Dixit VM, Turka LA. Lymphoid expression and regulation of A20, an inhibitor of programmed cell death. J Immunol 1995; 154: 1699-1706.

7. Opipari Jr AW, Hu HM, Yabkowitz R, Dixit VM. The A20 zinc finger protein protects cells from tumor necrosis factor cytotoxicity. J Biol Chem 1992; 267: 12424-12427.

8. Jaattela M, Mouritzen H, Elling F, Bastholm L. A20 zinc finger protein inhibits TNF and IL-1 signaling. J Immunol 1996; 156: 1166-1173.

9. Dixit VM, Green S, Sarma V, Holzman LB, Wolf FW, O'Rourke $\mathrm{K}$ et al. Tumor necrosis factor-alpha induction of novel gene products in human endothelial cells including a macrophage-specific chemotaxin. J Biol Chem 1990; 265: 2973-2978.

10. Opipari Jr AW, Boguski MS, Dixit VM. The A20 cDNA induced by tumor necrosis factor alpha encodes a novel type of zinc finger protein. J Biol Chem 1990; 265: 14705-14708.

11. Verstrepen L, Verhelst K, van Loo G, Carpentier I, Ley SC, Beyaert R. Expression, biological activities and mechanisms of action of A20 (TNFAIP3). Biochem Pharmacol 2010; 80: 2009-2020.

12. Skaug B, Chen J, Du F, He J, Ma A, Chen ZJ. Direct, noncatalytic mechanism of IKK inhibition by A20. Mol Cell 2011; 44: 559-571.

13. Haynesworth SE, Goshima J, Goldberg VM, Caplan Al. Characterization of cells with osteogenic potential from human marrow. Bone 1992; 13: 81-88.

14. Lin CS, Xin ZC, Deng CH, Ning H, Lin G, Lue TF. Defining adipose tissue-derived stem cells in tissue and in culture. Histol Histopathol 2010; 25: 807-815.

15. Pittenger MF, Mackay AM, Beck SC, Jaiswal RK, Douglas R, Mosca JD et al. Multilineage potential of adult human mesenchymal stem cells. Science 1999; 284: 143-147. 
16. Okada A, Yamasaki S, Koga T, Kawashiri SY, Tamai M, Origuchi T et al. Adipogenesis of the mesenchymal stromal cells and bone oedema in rheumatoid arthritis. Clin Exp Rheumatol 2012; 30: 332-337.

17. Moller DE. Potential role of TNF-alpha in the pathogenesis of insulin resistance and type 2 diabetes. Trends Endocrinol Metab 2000; 11: 212-217.

18. Cawthorn WP, Sethi JK. TNF-alpha and adipocyte biology. FEBS Lett 2008; 582: 117-131.

19. Ruan H, Hacohen N, Golub TR, Van Parijs L, Lodish HF. Tumor necrosis factor-alpha suppresses adipocyte-specific genes and activates expression of preadipocyte genes in 3T3-L1 adipocytes: nuclear factor-kappaB activation by TNF-alpha is obligatory. Diabetes 2002; 51: 1319-1336.

20. Yuan M, Konstantopoulos N, Lee J, Hansen L, Li ZW, Karin M et al. Reversal of obesity- and diet-induced insulin resistance with salicylates or targeted disruption of Ikkbeta. Science 2001; 293: 1673-1677.

21. Carcamo-Orive I, Gaztelumendi A, Delgado J, Tejados N, Dorronsoro A, Fernandez-Rueda J et al. Regulation of human bone marrow stromal cell proliferation and differentiation capacity by glucocorticoid receptor and AP-1 crosstalk. J Bone Miner Res 2010; 25: $2115-2125$.

22. Coornaert B, Baens M, Heyninck K, Bekaert T, Haegman M, Staal J et al. T cell antigen receptor stimulation induces MALT1 paracaspase-mediated cleavage of the NF-kappaB inhibitor A20. Nat Immunol 2008; 9: 263-271.

23. Duwel M, Welteke V, Oeckinghaus A, Baens M, Kloo B, Ferch U et al. A20 negatively regulates $T$ cell receptor signaling to NF-kappaB by cleaving Malt1 ubiquitin chains. $\mathrm{J}$ Immunol 2009; 182: 7718-7728.

24. Novotny NM, Markel TA, Crisostomo PR, Meldrum DR. Differential IL-6 and VEGF secretion in adult and neonatal mesenchymal stem cells: role of NFkB. Cytokine 2008; 43 215-219.

25. Hess S, Gottfried E, Smola H, Grunwald U, Schuchmann M, Engelmann H. CD40 induces resistance to TNF-mediated apoptosis in a fibroblast cell line. Eur J Immunol 1998; 28 3594-3604.
26. Janicke RU, Lee FH, Porter AG. Nuclear c-Myc plays an important role in the cytotoxicity of tumor necrosis factor alpha in tumor cells. Mol Cell Biol 1994; 14: 5661-5670.

27. Natoli G, Costanzo A, Guido F, Moretti F, Bernardo A, Burgio VL et al. Nuclear factor $\mathrm{kB}$-independent cytoprotective pathways originating at tumor necrosis factor receptorassociated factor 2. J Biol Chem 1998; 273: 31262-31272.

28. Adams M, Reginato MJ, Shao D, Lazar MA, Chatterjee VK. Transcriptional activation by peroxisome proliferator-activated receptor gamma is inhibited by phosphorylation at a consensus mitogen-activated protein kinase site. J Biol Chem 1997; 272: 5128-5132.

29. Chae GN, Kwak SJ. NF-kappaB is involved in the TNF-alpha induced inhibition of the differentiation of 3T3-L1 cells by reducing PPARgamma expression. Exp Mol Med 2003; 35: 431-437.

30. Tominaga S, Yamaguchi T, Takahashi S, Hirose F, Osumi T. Negative regulation of adipogenesis from human mesenchymal stem cells by Jun $\mathrm{N}$-terminal kinase. Biochem Biophys Res Commun 2005; 326: 499-504.

31. Harhaj EW, Dixit VM. Deubiquitinases in the regulation of NF-kappaB signaling. Cell Res 2011; 21: 22-39.

32. Carcamo-Orive I, Tejados N, Delgado J, Gaztelumendi A, Otaegui D, Lang V et al. ERK2 protein regulates the proliferation of human mesenchymal stem cells without affecting their mobilization and differentiation potential. Exp Cell Res 2008; 314: 1777-1788.

(c) (i) (2) Cell Death and Disease is an open-access journal By $\mathrm{NC}$ sA published by Nature Publishing Group. This work is licensed under a Creative Commons Attribution-NonCommercialShareAlike 3.0 Unported License. To view a copy of this license, visit http://creativecommons.org/licenses/by-nc-sa/3.0/ 